\section{ESSENTIAL TO YOUR \\ PATIENTS' TOOLKIT}

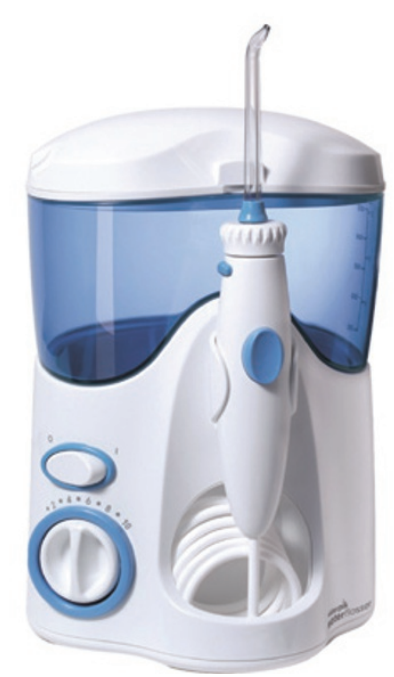

Providing an effective and affordable adjunct to your patients' oral health regimes, the WP 120 Ultra Water Flosser from Waterpik International Inc is the perfect solution.

As the latest of the high-performance water flossers from Waterpik, the newly refined WP 120 is now readily available throughout the country with a two-pin plug for easy charging in any UK shaver socket.

As Waterpik Water Flossers are also clinically proven to be up to 50\% more effective than traditional string floss at improving gingival health, you can be sure that your patients have the very best tools to achieve and maintain their oral health.

Discover the WP 120 Ultra Water Flosser from Waterpik International Inc. and find out what your patients are missing out on today.

For more information on Waterpik Water Flossers speak to your wholesaler or visit www.waterpik.co.uk. Waterpik products are widely available in Boots stores and selected Lloyds Pharmacies.

\section{TRADITIONAL IMPRESSIONS NOT NEEDED}

Traditional time consuming and often messy impressions are no longer needed when you opt for the CEREC 3D CAD/CAM System.

The CEREC System takes an optical impression of the preparation and the antagonist, resulting in probably the most accurate impression you will ever have taken. To allow you complete control of the finished prosthesis you specify the positions of the margins and the proximal contacts. The CEREC system goes on to swiftly fabricate the crown, inlay, onlay or veneer accurately, quickly and to the very highest quality. CEREC automatically accurately computes the occlusal contacts referring to the antagonist to do so resulting in the perfect fit.

The CEREC 3D CAD/CAM System will help you to produce probably the best ceramic restorations possible. You will find the fit to be superb as the margin for error has been removed, the function, wear, durability and aesthetics of a CEREC prosthesis is second to none. In addition, this high-tech piece of equipment allows you to place the new prosthesis in the same visit saving you and your patient time and laboratory fees and any embarrassment at having to wear a temporary whilst waiting for the final prosthesis to be fitted.

To find out more and for a demonstration contact Sirona Dental Systems Limited on 0845071 5040 or email: info@sironadental.co.uk. www.sironadental.co.uk

\title{
NEUTRALISING THE SUGAR ACID IN PLAQUE
}

Colgate's ground-breaking new Maximum Cavity Protection Toothpaste plus Sugar Acid Neutraliser Toothpaste set a new standard of care in everyday cavity protection for individuals and families, providing a new approach to address the major oral health challenge that is caries.

As children grow older and gain more independence, free sugar (glucose) consumption in their diet and repeated snacking can increase, whilst at the same time they can become less careful about their oral health as parental supervision decreases.

Colgate Maximum Cavity Protection plus Sugar Acid Neutraliser uses the first and only Sugar Acid Neutraliser technology to directly target acids produced from free sugar in plaque. Supported by eight years of clinical research involving 14,000 subjects, Colgate Maximum Cavity Protection toothpaste with
Sugar Acid Neutraliser technology has been clinically proven to provide greater cavity protection versus regular everyday fluoride toothpaste.

Colgate's unique Sugar Acid Neutraliser technology is powered by arginine, a naturally occurring amino acid. The arginine is metabolised by other plaque bacteria to produce base. This helps to neutralise the damaging acids produced by the breakdown of dietary free sugars, helping to restore $\mathrm{pH}$ in the plaque biofilm to a more neutral and healthier level.

Colgate Maximum Cavity Protection plus Sugar Acid Neutraliser provides an effective everyday solution for the whole family to help fight the development of caries now and in years to come. All variants in this new toothpaste range contain $1450 \mathrm{ppm}$ F, including a Kids variant which benefits from a milder mint flavour to make it more acceptable to younger children.

To find out more, visit and register at www.colgateprofessional.co.uk.

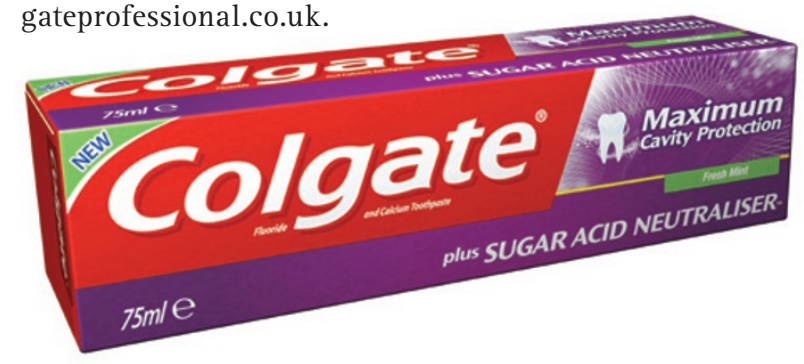

\section{MOUSSE WITH THE TASTES OF SUMMER}

GC Tooth Mousse is a water based sugar free topical cream that will provide extra protection for patients teeth. The twice daily use of GC Tooth Mousse produced a 19\% reduction in enamel demineralisation.
The CPP-ACP in Tooth Mousse binds to biofilms, plaque, bacteria, hydroxyapatite and surrounding soft tissue localising bio-available calcium and phosphate. Saliva also enhances the effectiveness of
CPP-ACP and the flavour helps stimulate saliva.

GC Tooth Mousse is available in Strawberry, Melon, Vanilla, Mint and Tutti Frutti. Call 01908218999 oremailinfo@uk.gceurope.com. 